\title{
NR12 adaptation of the embroidery machine in a Manaus industry
}

\section{Vilson Feleol da Mota $^{1}$}

\author{
${ }^{1}$ Laureate International Universities (UNINORTE). Av. Joaquim Nabuco, 1270, Centro, Manaus - AM Brasil, CEP:69020-030 \\ Email: evailton.andrade@uninorte.com.br
}

\author{
Received: August $10^{\text {th }}, 2017$ \\ Accepted: September 25 th, 2017 \\ Published: September 30 ${ }^{\text {th }}, 2017$ \\ Copyright $\odot 2016$ by authors and Institute \\ of Technology Galileo of Amazon (ITEGAM). \\ This work is licensed under the Creative \\ Commons Attribution International \\ License (CC BY 4.0). \\ http://creativecommons.org/licenses/by/4.0/ \\ (c) (1) (2) Open Acces:
}

\begin{abstract}
This article aims to present technical measures taken to adapt to NR 12 in a factory in the Industrial District, describing the risks present in the operations and the solutions of operational improvements of machines, equipment and installations of safety devices and protections. The solutions presented in this study aim to comply with the requirements of Regulatory Norm NR 12, in order to preserve the health and physical integrity of all employees. The results perceived in this adaptation were the increase of the confidence of the employees in their work environment, the mitigation of the risks within the labor area, the improvement of the organization of the productive layout.

It is concluded that compliance with the standard is necessary because it brings benefits to both the employees and the employer of this plant.
\end{abstract}

Keywords: NR 12, adequacy, Safety, Embroidery machine.

\section{Adequação da NR12 da bordadeira de bancada em uma indústria de Manaus RESUMO}

Este artigo tem por objetivo apresentar medidas técnicas tomadas para adequação à NR 12 em uma fábrica no Distrito Industrial, descrevendo os riscos presentes nas operações e as soluções de melhorias operacionais de máquinas, equipamentos e instalações de dispositivos de segurança e proteções. As soluções apresentadas neste estudo visam cumprir as exigências da Norma Regulamentadora NR 12, com o intuito de preservar a saúde e a integridade física de todos os colaboradores. Os resultados percebidos nesta adequação foram o aumento da confiança dos colaboradores em seu ambiente de trabalho, a mitigação dos riscos dentro da área laboral, a melhoria da organização do layout produtivo. Conclui-se que a adequação à norma se faz necessária por trazer benefícios tanto aos empregados quanto ao empregador desta fábrica.

Palavras-chave: NR 12, Adequação, Segurança, Bordadeira de Bancada.

\section{INTRODUÇÃO}

A Norma Regulamentadora NR 12, publicada em 1978, foi elaborada com o intuito de definir referências técnicas, princípios fundamentais e medidas de proteção para garantir a saúde e a integridade física dos trabalhadores. Com a evolução de métodos e processos esta Norma está em constante atualização para poder suprir as necessidades apresentadas.

A NR 12, cita: “... estabelece requisitos mínimos para a prevenção de acidentes e doenças do trabalho nas fases de projeto e de utilização de máquinas e equipamentos de todos os tipos, e ainda à sua fabricação, importação, comercialização, exposição e cessão a qualquer título, em todas as atividades econômicas, sem prejuízo da observância do disposto nas demais Normas Regulamentadoras - NR aprovadas pela Portaria n. ${ }^{\circ} 3.214$, de 8 de junho de 1978, nas normas técnicas oficiais e, na ausência ou omissão destas, nas normas internacionais aplicáveis."

A fábrica "X", situada na Rua Jutaí - Distrito Industrial I, Manaus - AM, 69075-130, do ramo da colchoaria vinha apresentando problemas de ordem legal, tendo sido autuada pelo Ministério do Trabalho devido a não adequação à NR 12 [1].

A fim de regularizar a situação da fábrica, evitando assim o seu embargo, fez-se necessária ação corretiva de acordo com os seguintes tópicos da norma: arranjo físico e instalações, instalações e dispositivos elétricos, dispositivos de partida, acionamento e parada, sistemas de segurança, dispositivos de parada de emergência, manutenção, inspeção, preparação, ajuste, reparo e limpeza, sinalização e manuais.

No dia 12 de Janeiro de 2017 foram publicadas no Diário Oficial algumas mudanças no DOU relativa à fiscalização. A 
norma sempre foi alvo de discussão pelo fato da alta fiscalização sobre as empresas, buscando aumentar a segurança da utilização das máquinas, a mudança principal estabelecida no Diário foi a questão do prazo para regulamentação.

No que tange a adequação à NR 12 em uma fábrica no Distrito Industrial de Manaus, a necessidade inicial foi suprida por ações conjuntas entre empregado e empregador para sanar todas as deficiências apontadas no auto de infração recebido pela distinta fábrica.

\section{REVISÃO BIBLIOGRÁFICA}

\section{II.1 NR 12}

A segurança do trabalho é um tema que vem sendo amplamente abordado tanto dentro do contexto histórico brasileiro como mundial, e tendo em vista a adaptação à globalização e a evolução industrial, este assunto vem conquistando uma abordagem ainda mais normatizada e moderna.

A importância da Segurança para o trabalhador está intrínseca dentro dos valores da sociedade atual, no entanto, sua importância está muito além, visto que dependendo dos motivos que levem ao acidente e sua gravidade, altíssimos custos são direcionados ao empregador e não simplesmente à previdência, gerando assim uma série de danos conjuntos [2]: "O que não podemos seguir assistindo é a utilização dos recursos gerais, carreados ao orçamento da seguridade social, para financiamento das prestações decorrentes de acidentes do trabalho cujo custeio deve ser feito exclusivamente pelas empresas".

Uma das maiores dificuldades dentro deste campo profissional é conscientizar tanto o empregado quanto o empregador da importância de medidas voltadas à garantia da segurança do trabalhador, devido ao descaso com a legislação ou mesmo falta de organização que ainda é notada em alguns setores. Balera aponta que "o número de acidentes de trabalho ocorridos no Brasil é uma estatística desconhecida porque, acredita o autor, a sociedade convive com a subnotificação. As estatísticas oficiais já um pouco ultrapassadas dos organismos internacionais situam o Brasil como campeão mundial dos acidentes do trabalho".

Tendo em vista tal cenário, é evidente a importância das 36 Normas Regulamentadoras da Segurança do Trabalho. As NR's, como são conhecidas, tem a finalidade de regulamentar e fornecer informações sobre procedimentos obrigatórios que estejam relacionados à Segurança e a Medicina do Trabalho, e todas são embasadas em padrões internacionais de proteção [3]: "Normas Regulamentadoras são instrumentos legais editados pelo Ministério do Trabalho e Emprego, que norteiam as obrigações dos estabelecimentos de qualquer natureza em relação a medicina e a segurança do trabalhador, e cujo não cumprimento pode resultar em multa, notificação ou interdição do estabelecimento."

A primeira publicação das Normas Regulamentadoras aconteceu no final da Década de 1970, obrigando empresas e indústrias a cumprirem e fazerem cumprir normas de Segurança do Trabalho.

Neste artigo em particular, trataremos especificamente da adequação à Norma Regulamentadora 12, que aborda o tema Proteção de Máquinas e Equipamentos. A NR 12 define as referências, técnicas, princípios fundamentais e medidas de proteção para garantir a saúde e a integridade física dos trabalhadores que lidam com máquinas e equipamentos [4]: “A industrialização no Brasil na década de 70, gerou impactos sociais e econômicos, e um dos fatores que mais impactou na economia foi a criação de larga escala de máquinas operatrizes, como prensas, guilhotinas, cilindros e calandras, sendo estas com acesso fácil as partes perigosas não havendo os dispositivos apropriados de segurança, deixando o Brasil em primeira colocação em acidentes de trabalho mundial naquela época. E ainda hoje se encontra entre os dez países em que mais ocorrem acidentes no setor industrial".

O Ministério do Trabalho e do Emprego (MTE) é a autoridade regulamentadora sobre segurança e saúde no trabalho. A CLT - Consolidação das Leis do Trabalho - considera obrigação legal para os empregadores a Lei $n^{\circ} 6.514 / 77$ relativa à segurança e medicina do trabalho e outras providências, especificamente para os fabricantes de bens de capital a seção XI - Das Máquinas e Equipamentos, os Artigos 184, 185 e 186 da CLT.

A Norma Regulamentadora 12 está regulamentada na Lei $\mathrm{n}^{\circ}$ 6.514/77, especificamente na seção XI - Das Máquinas e Equipamentos, os Art. '184, 185 e 186 da CLT. A primeira publicação da NR 12 ocorreu em 08 de Junho de 1978, pela Portaria $\mathrm{GM} \mathrm{n}^{\circ}$ 3.214. A atualização no contexto do corpo da NR 12 foi publicada em 17 de dezembro de 2010, pela Portaria SIT $n^{\circ}$ 197. O último anexo (Anexo XII) foi inserido na norma e publicado em 08 de dezembro de 2011, pela Portaria SIT no 293. A última atualização da NR 12 foi publicada pela Portaria $n^{\circ} 1.893$ de 09 de Dezembro de 2013.

Para identificação, projeto e instalação de medidas de segurança de máquinas e equipamentos são empregados as seguintes Normas:

- Equipamentos de parada de emergência: A finalidade desta Norma é especificar os requisitos funcionais que devem ser cumpridos pelo equipamento de parada de emergência, para atender os requisitos essenciais de segurança (NBR 13759);

- Prevenção de partida inesperada: Esta Norma fornece aos projetistas de máquinas e comitês técnicos, encarregados do trabalho de preparação de normas técnicas sobre segurança de máquinas, uma vista geral de medidas incorporadas ao equipamento, com a finalidade de impedir a partida inesperada (NBR 14154);

- Proteções fixas e móveis;

-Dispositivos de Intertravamento associado às proteções: A finalidade básica desta Norma é servir de guia para projetistas de máquinas e redatores de normas tipo $\mathrm{C}$, em como projetar ou selecionar dispositivos de intertravamento associados a proteções. Pode também ser usada, como um guia no controle do risco, onde não houver normas do tipo $\mathrm{C}$, para um tipo de equipamento em particular [5];

- Folgas mínimas para evitar esmagamento de partes do corpo humano.

Para um melhor entendimento do processo necessário para adequação é importante entender as ações prioritárias relativas a NR 12 e suas respectivas ordens cronológicas dentro do projeto, de acordo com a NR 12.

A seguir serão apresentadas as etapas para o início da adequação para todas as empresas:

1. A empresa deve estar Regularizada com Registro no CREA: Capitulo 12.123, alínea "d" da NR-12, lei no 5.194, de 24 de dezembro de 1966, resolução n ${ }^{\circ} 218$, de 29 de junho de 1973 - CONFEA, lei $n^{\circ} 6.496$, de 07 de dezembro de 1977, lei $\mathrm{n}^{\circ} 6.839$, de 30 de outubro de 1980, resolução $n^{\circ} 336$, de 27 de outubro de 1985 - CONFEA, resolução nº 1.048, de 14 de agosto de 2013 CONFEA.

2. A empresa deve ter Responsável Técnico: Capítulo 12.30, da NR-12, lei n ${ }^{\circ} 5.194$, de 24 dez de 1966, lei nº 6.496, de $07 \mathrm{dez}$ de 1977.

3. Inventário de Máquinas e Equipamentos Localizados e m Planta Baixa: Capítulo-12.153 da NR-12, manter o inventário atualizado com o seguinte conteúdo mínimo: a) Identificação da máquina e equipamento; b) Descrição geral (tipo, fabricante, modelo, características); c) Capacidade, produtividade, tempo de operação por dia, operadores envolvidos; d) Diagnóstico com relação a NR-12 (sistema de segurança); e) 
Previsão da adequação; f) Recursos financeiros para a adequação; g) Localização em planta baixa (layout).

4. Análise de Riscos: Capítulo 12.39, alínea "a" da NR-

12.

5. Emissão da ART: Capítulo 12.39, alínea "b" da NR12, lei n 6.496, de 07 de dezembro de 1977.

Outro ponto importante a ressaltar é a respeito dos prazos de adequação, que diferem de acordo com a "idade" da máquina ou equipamento.

- Para máquinas novas adquiridas antes da Portaria $\mathrm{N}^{\circ}$ 197 de 17/12/2010 a responsabilidade cabe a quem adquiriu realizar a adequação das máquinas para atender aos requisitos e exigências contidas na NR-12, conforme Portaria $n^{\circ} 197$ de 17/12/2010, corpo da Norma e seus Anexos. Já para máquinas ou equipamentos adquiridos depois da Portaria n ${ }^{\circ} 197$ de 17/12/2010 a responsabilidade recai sobre o fornecedor/fabricante adequar a máquina para atender aos requisitos e exigências contidas na NR 12.

- Para máquinas usadas adquiridas antes e depois da Portaria $n^{\circ} 197$ de 17/12/2010 a responsabilidade recai a quem adquiriu adequar a máquina para atender aos requisitos e exigências contidas na NR 12, conforme Portaria $n^{\circ} 197$ de 17/12/2010, corpo da norma e seus anexos.

Em se tratando de dispositivos de segurança temos:

- Proteções Fixas: Proteção mantida em sua posição (isto é fechada), permanentemente (por solda, etc.) ou por meio de fixadores (parafusos, porcas, etc.) tornando sua remoção ou abertura impossível, sem o uso de ferramentas;

- Proteções Móveis: Geralmente estão vinculadas à estrutura da máquina ou elemento de fixação adjacente, por meios mecânicos, (por exemplo, basculantes ou deslizantes) que pode ser aberta sem o auxílio de ferramentas;

- Chaves de Segurança: Dispositivos usados geralmente em proteções móveis que quando for aberta interrompe seu ciclo de trabalho e a mantém parada, após ser fechada a proteção, a máquina poderá ser acionada novamente;

- Comando Bi manual: Requer o acionamento simultâneo com as duas mãos do operador inibindo que suas mãos não estarão na área de risco, devem estar em altura adequada a postura ergonômica do operador, para prevenir burla a distância mínima entre os botões deve estar maior do que a distância entre a mão e o cotovelo ou ultrapassando $550 \mathrm{~mm}$, outro método de impedir a burla é a colocação de abas sobre os botões de acionamento;

- Chave Geral: Todo equipamento que possuir energia elétrica de fonte externa devem possuir chave geral localizada em local de fácil acesso e que evite o acionamento acidental e proteja a as suas partes energizadas;

Sistemas de Transmissão: Destaca-se que as partes móveis e de transmissão de movimentos devem permanecer sempre enclausuradas dentro da estrutura da máquina, sendo que a mesma possua uma chave de segurança, onde que quando for aberta esta venha a interromper o funcionamento da máquina.

\section{II.2 A IMPORTÂNCIA DA SEGURANÇA DO TRABALHO NAS ORGANIZAÇÕES}

A Segurança do Trabalho é um conjunto de ciências e tecnologias que buscam a proteção do trabalhador em seu local de trabalho, no que se refere à questão da segurança e da higiene do trabalho. Seu objetivo básico envolve a prevenção de riscos e de acidentes nas atividades de trabalho visando a defesa da integridade da pessoa humana [6].

Além da saúde do trabalhador a empresa estende seus cuidados no Ambiente e as condições de trabalho, visando proporcionar conforto e segurança na execução das atividades. São feitos investimentos diversos quanto aos Equipamentos de Proteção Individual - EPI'S e no ambiente [7].
Uma empresa precisa constituir equipe de Segurança do Trabalho porque é exigido por lei. Por outro lado, a Segurança do Trabalho faz com que a empresa se organize, aumentando a produtividade e a qualidade dos produtos, melhorando as relações humanas no trabalho. Existe uma ampla legislação sobre Segurança e Saúde no Trabalho, especialmente na área trabalhista e previdenciária [8].

Inicialmente temos a Constituição Federal que enfatiza em seu Capítulo II (Dos Direitos Sociais), artigo $6^{\circ}$ e $7^{\circ}$, incisos XXII, XXIII, XXVIII e XXXIII dispõe, especificamente, sobre segurança e saúde dos trabalhadores.

A Consolidação das Leis do Trabalho - CLT dedica o seu Capítulo V à Segurança e Medicina do Trabalho, de acordo com a redação dada pela Lei 6.514, de 22 de dezembro de 1977 [9].

Na CLT os artigos 154 a 223, estão voltados a essa questão, sendo de estrema "concorrência" a competência para legislar sobre o assunto, que encontra-se entre a União, os Estados e o Distrito Federal, conforme $\mathrm{CF}$, art. 24, XII). A competência da União limita-se a estabelecer normas gerais. Isso, no entanto, não exclui a competência suplementar dos Estados.

Inexistindo lei federal sobre normas gerais, os Estados exercerão a competência legislativa plena, para atender às suas peculiaridades. A superveniência de lei federal sobre normas gerais suspende a eficácia da lei estadual, no que lhe for contrário (CF, art. $24, \S \S 1^{\circ}$ ao $4^{\circ}$ ).

Através da CLT, podemos perceber que a Segurança e Medicina do Trabalho deverá está presente em todos os locais de trabalho, não desobrigando as empresas do cumprimento de outras disposições que, com relação à matéria, sejam incluídas em códigos de obras ou regulamentos sanitários do Estados ou Municípios em que se situem os respectivos estabelecimentos, bem como daquelas oriundas de convenções coletivas de trabalho.

A CLT busca resumir a Segurança e Medicina do Trabalho em todas as áreas de mercado, onde tenta prevê as mais diversas situações, passando deste de "equipamentos de proteção individual", até "das caldeiras, fornos e recipientes sob pressão". Ficando claro que, dúvidas sempre surgirão, para isso há uma continuidade na legislação, aperfeiçoando e modernizando todo o processo "legal".

O Ministério do Trabalho, por intermédio da Portaria n. ${ }^{\circ}$ 3.214, de 08 de junho de 1978, aprovou as Normas Regulamentadoras - NR, previstas no Capítulo V da CLT. Esta mesma Portaria estabeleceu que as alterações posteriores das NR seriam determinadas pela Secretaria de Segurança e Saúde do Trabalho, órgão do MT.

Já a Segurança do Trabalho rural tem regulamentação específica através da Lei n. ${ }^{\circ}$ 5.889, de 05 de junho de 1973, cujas Normas Regulamentadoras Rurais - NRR foram aprovadas pela Portaria n. ${ }^{\circ}$ 3.067, de 12 de abril de 1988 MT, 1995.

Incorporam-se as leis brasileiras, as Convenções da OIT - Organização Internacional do Trabalho, quando promulgadas por Decretos Presidenciais. As Convenções Internacionais são promulgadas após submetidas e aprovadas pelo Congresso Nacional [10].

Além disso, há a legislação acidentaria pertinente à área da Previdência Social. Onde se estabelecem os critérios das aposentadorias especiais, do seguro de acidente do trabalho, indenizações e reparações.

Completando essa extensa legislação, devemos lembrar que a ocorrência dos acidentes (lesões imediatas ou doenças do trabalho) pode dar origem a ações civis e penais, concorrendo com as ações trabalhistas e previdenciárias [11].

\section{II.3 SGSST - SISTEMAS DE GESTÃO DE SAÚDE E SEGURANÇA DO TRABALHO}


Com a publicação da Lei Federal $n^{\circ}$ 6514/77, que alterou o Cap. V do Tít. II da CLT - Consolidação das Leis Trabalhistas e da Portaria 3214/78, que aprovou as Normas Regulamentadoras (NR), relativas à SST - Saúde e Segurança do Trabalho, houve um grande salto rumo a melhores condições de trabalho.

Sensível evolução ocorreu nas décadas de 80 e 90, com as alterações das normas referentes às práticas de SST, principalmente com o PPRA - Programa de Prevenção de Riscos Ambientais (NR n ${ }^{\circ}$ 9) e o PCMSO - Programa de Controle Médico de Saúde Ocupacional (NR no 7). O PPRA visa a preservação da saúde e da integridade física dos trabalhadores através da antecipação, reconhecimento, avaliação e consequente controle da ocorrência de riscos reais ou potenciais do ambiente de trabalho. O PCMSO, que deve estar em sintonia com o PPRA, tem como objetivo a promoção e preservação da saúde do conjunto dos trabalhadores. Outra evolução ocorreu com a criação da CIPA - Comissão Interna de Prevenção de Acidentes (NR n ${ }^{\circ}$ 5), cuja finalidade é, através da ação dos próprios trabalhadores, promover a melhoria das condições dos ambientes de trabalho.

Dos diversos elementos que compõem um programa de gestão de Segurança e Saúde no Trabalho - SST, os três aqui apontados - cultura, ferramentas e objetivos -, se avaliados conforme a importância, sem dúvida, os aspectos culturais representam, de longe, o que há de mais significativo, facilitando, inibindo ou inviabilizando seu sucesso [7]. Por mais elaborado que seja um programa de SST e por melhores que sejam as ferramentas por ele disponibilizadas para o diagnóstico e a solução dos riscos do trabalho, se não houver disposição e participação compromissada de todos os envolvidos em suas ações, especialmente do corpo gerencial da empresa, os resultados por ele produzidos serão limitados, tanto do ponto de vista quantitativo, quanto qualitativo [12].

No entanto, em função dos traços da cultura de SST ainda predominante na maioria das empresas brasileiras, mesmo nas de grande porte, a questão da segurança e saúde no trabalho não é tratada como deveria ser, tanto por parte da empresa, como por parte dos trabalhadores.

Alguns problemas que norteiam a não conformidade dos programas de programas de SST nas empresas compreendem, principalmente o envolvimento da alta administração da empresa; a orientação desses programas quando voltada para o cumprimento da legislação, o 'ato inseguro' como causa preponderante de acidentes, o comportamento do trabalhador e sua relação com a organização, postura das chefias, entre outros [13].

Os valores organizacionais motivam as empresas a atribuírem importância a SST sob duas perspectivas: o alcance dos objetivos organizacionais e o exercício da responsabilidade social. Esta combinação concede vantagens competitivas na promoção da segurança do trabalho [14].

\section{MATERIAIS E MÉTODOS}

Descrevem-se neste tópico os procedimentos metodológicos adotados para a elaboração deste artigo. A presente pesquisa tem caráter exploratório-descritivo e quantitativo. Ressalta-se, também, que a metodologia é de grande relevância em uma pesquisa científica, uma vez que se trata de uma etapa preponderante para o alcance dos objetivos outrora propostos.

As pesquisas exploratórias são aquelas que têm por objetivo explicitar e proporcionar maior entendimento acerca de um determinado problema. Neste tipo de pesquisa procura-se, também, um maior conhecimento sobre o tema de estudo, sendo realizadas pesquisas para atender a uma necessidade de ordem intelectual ou razões práticas, nas quais o pesquisador pretende desvendar aspectos da realidade que estão a sua volta apenas para atender uma satisfação própria, ou seja, ampliar conhecimentos [15].

No que tangem as questões práticas, estas pesquisas visam à realização de algo de forma mais eficiente. Pode também apresentar uma investigação de ordem intelectual no decorrer de sua realização. A pesquisa exploratória, quanto aos fins, é realizada em área na qual há pouco conhecimento científico acumulado ou sistematizado. Por tratar-se de uma pesquisa que busca explorar conceitos e fatos de pouca bibliografia, é um estudo novo. Além disso, por sua natureza de sondagem, não comporta hipóteses que poderão, todavia, surgir durante a pesquisa ou ao seu final. Além disso, pretende-se descrever as características de um fenômeno [16].

A pesquisa é descritiva, quanto aos fins, expõe características de determinado fenômeno. Neste trabalho, buscouse expor as características que compõem os conceitos e benefícios implantação da NR 12 no processo de utilização da Bordadeira de Bancada, quesito autuado pelo Ministério do Trabalho por inadequação na Fábrica X da Amazônia. Não tem o compromisso de explicar os fenômenos que descreve, embora sirva de base para algumas explicações.

A pesquisa classifica-se, ainda, como quantitativa uma vez que valeu-se de instrumentos estatísticos no processo de análise de seu problema. Sobre estes tipos de pesquisa, é uma forma adequada para o conhecimento da natureza de um fenômeno social, haja vista o pesquisador coletar os dados na realidade pesquisada para, posteriormente, analisá-los de forma indutiva.

Neste sentido, afirma-se que a presente pesquisa utilizouse do método de coleta de dados a respeito dos procedimentos utilizados no manuseio do equipamento citado, e sua adequação à NR 12, com atendimento à autuação dada pelo Ministério do Trabalho em Janeiro de 2017.

Foram destacadas observações e adequações implantadas no manuseio do referido equipamento e seus benefícios junto à organização objeto desta pesquisa.

Nesta perspectiva, o presente trabalho buscou delinear conceitos bibliográficos e apontamentos de melhoria acerca da temática no intuito de responder à problemática em questão. A legitimidade adequação de procedimentos à NR 12 é uma premissa que necessita de análises e aplicabilidade de instrumentos eficazes na construção de conhecimentos, no sentido de melhorar e evidenciar a eficácia dos métodos utilizados pela Fábrica X da Amazônia, quanto à seguridade e saúde de seus colaboradores, uma vez que se trata de importantes argumento no que tange à eficiência de seus processos organizacionais junto às entidades normativas.

Durante a pesquisa foi possível observar a ausência da aplicabilidade a NR12 sobre o procedimento de utilização da Bordadeira de Bancada, equipamento utilizado por colaboradores treinados, porém não capacitados com as diretrizes regulamentares de segurança.

Foram observadas, também, a ausência de manuais técnicos e regulamentados de utilização do equipamento, bem como a ausência de certificações da NR12 para o manuseio da Bordadeira de Bancada, o eu poderia acarretar em acidentes de trabalhos fatais, além da autuação imposta pelo Ministério do Trabalho.

Com isto, foi possível, graças ao entendimento da alta direção da Fábrica X da Amazônia, a elaboração, execução, implantação, treinamento e certificação da NR12, sobre o manuseio do equipamento em questão, bem como garantir melhores resultados nos processos de fabricação e produção dos colchões 


\section{RESULTADOS E DISCUSSÕES}

O equipamento sofreu duas alterações básicas em seu projeto inicial para atender as normas de segurança vigentes. Foram incluídos Relés de Segurança da Marca Schmersal Modelo SRB-301MC com duplicidade de contatoras para assegurar a desenergização total do Equipamento em caso de acionamento de qualquer uma das 2 Botoeira de Emergência disponível na parte frontal da máquina. Também foram instalados 1 Cortina de Luz de Segurança Schmersal Modelo SLC 420 para assegurar o desacionamento do equipamento caso o operador tente se aproximar das agulhas quando as mesmas estiverem em funcionamento.

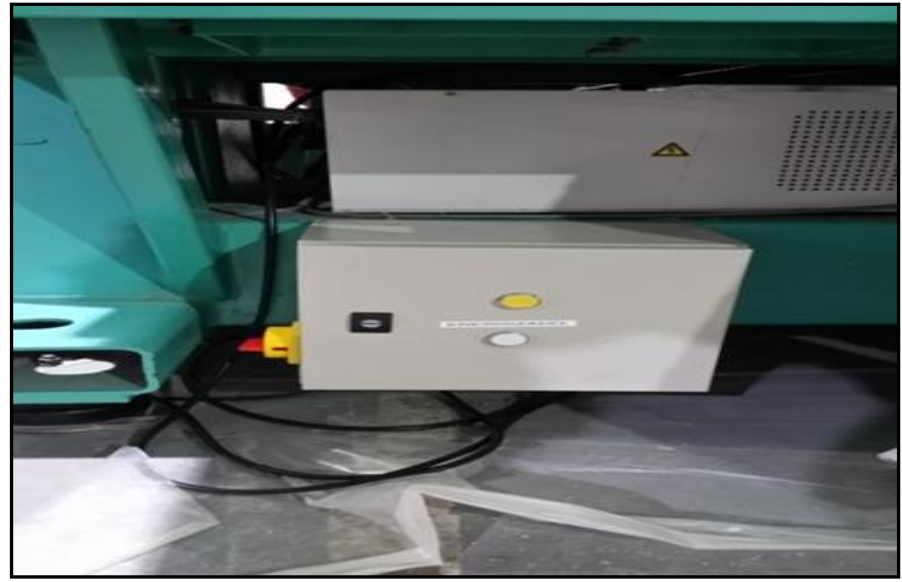

Figura 1: Quadro de comando.

Fonte: Autor, (2017).

Este Quadro de comando (Fig.1) está localizado abaixo da bancada na parte traseira do equipamento e ele é responsável por fazer com que as alterações feitas no equipamento funcionem. Sem ele ou com ele desligado, o equipamento não é capaz nem de ao menos ser ligado. Nele está contido os Relés de Segurança (RS1 e RS2), Contatoras (K1 e K2), Chave Lock Geral (SW1), Fonte de Alimentação (T1) e Disjuntor (F1).

\section{IV.1 INCLUSÃO DOS BOTÔES DE EMERGÊNCIA}

Foram incluídas duas Botoeiras de Emergência no equipamento Schneider Modelo XB4BC42 com trava e com dois contatos NF para atender a norma. Todos eles estão ligados em série seguindo para os 2 canais do Relé de Segurança RS1. Caso a Botoeira de Emergência seja pressionada, o equipamento será completamente desenergizado e parará imediatamente suas atividades.

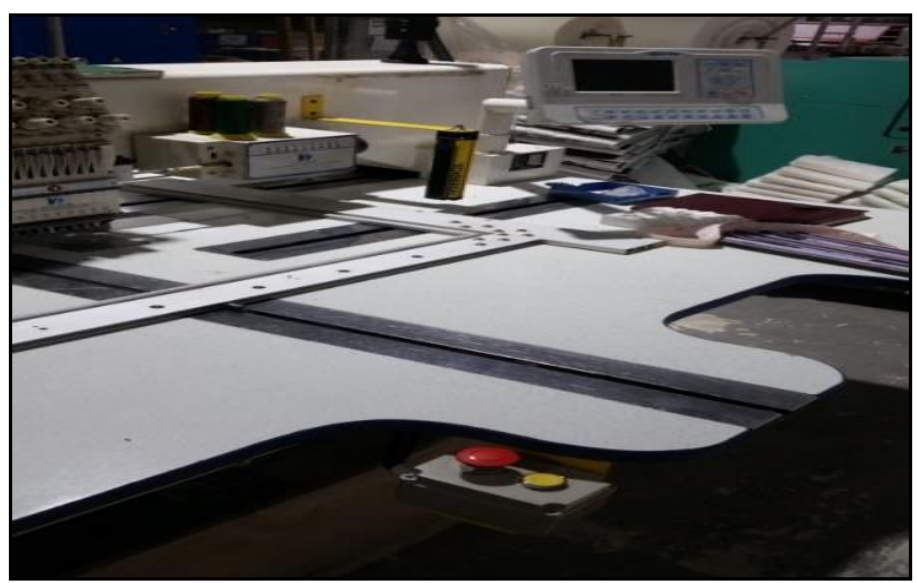

Figura 2: Bancada com botoeira de emergência.

Fonte: Autor (2017).

\section{IV.2 INCLUSÃO DE DOIS BOTÕES DE RESET}

Foram incluídas caixas plásticas com os botões de Reset e Emergência na parte frontal de fácil acesso ao Operador consiga pressioná-los em caso de Emergência ou para Resetar o equipamento em caso de corte na Barreira de Cortina de Luz de Segurança, caso o Operador abra qualquer uma das portas o equipamento parará seu funcionamento imediatamente, onde, ao fechar as portas, ele obrigatoriamente deverá pressionar o Botão Reset S2, S3 ou S4 antes de pressionar o botão Start para o equipamento voltar a funcionar, caso o mesmo não pressione o botão Reset, não acontecerá nada se apertar o botão Start.

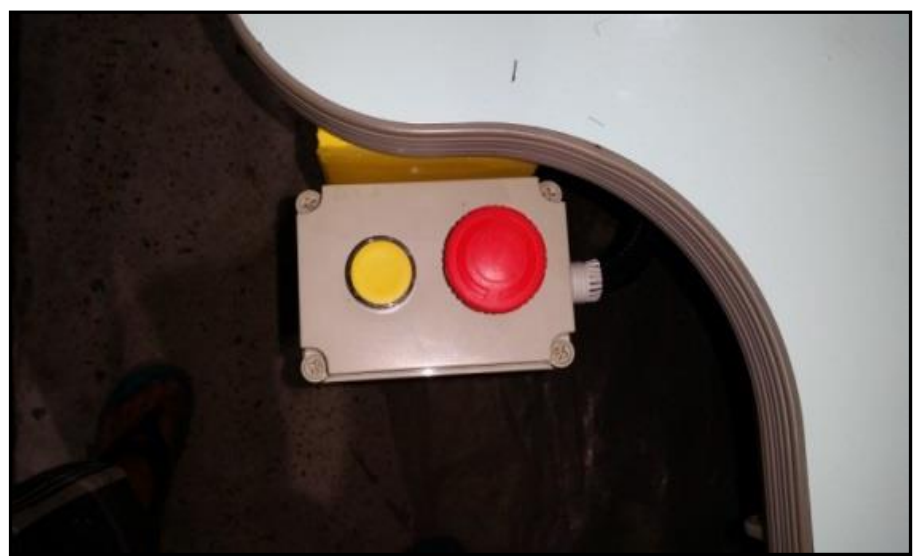

Figura 3: Botões reset.

Fonte: Autor, (2017).

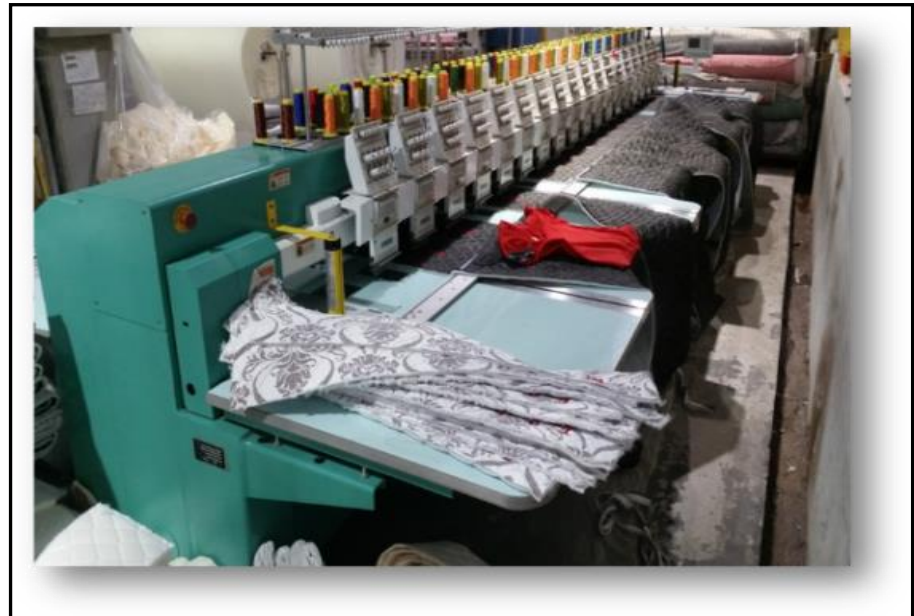

Figura 4: Bordadeira de Bancada.

Fonte: Autor, (2017).

As modificações físicas na bordadeira de bancada são as principais adequações do objeto de estudo, no entanto outros itens como qualificação dos colaboradores para a operação da máquina também estão dentro dos resultados obtidos neste objeto de estudo.

\section{CONCLUSÃO}

Levando-se em conta o que foi observado pode-se concluir que a parte principal das adequações está nas modificações feitas pelo empregador em máquinas e equipamentos dentro da área de trabalho. Atendendo o item 12.24 da NR12 em estudo. É imprescindível que todos se conscientizem de que as alterações solicitadas na NR são necessárias não somente para atender Leis Trabalhistas e sim o bem-estar do colaborador, sendo um ato de cidadania, dando meios ao nicho de funcionários que trabalham diariamente naquela fábrica. 
Este artigo portanto enriquece os estudos acerca da Segura e Saúde do Trabalho tanto no campo acadêmico quanto no profissional, dando conhecimento no que refere-se a adequação de máquinas e equipamentos citado na NR12.

\section{AGRADECIMENTOS}

A Uninorte Laureate International Universities (UNINORTE) pelo apoio à pesquisa.

\section{REFERÊNCIAS}

[1] NR 12. Norma Regulamentadora No 12-Segurança no Trabalho em Máquinas e Equipamentos. Disponível em: <http://www.trabalho.gov.br/images//Documentos/SST/NR/NR1 2/NR-12.pdf > Acesso em: 15/02/2017.

[2] Balera, W. Acidentes de trabalho devem ser retirados dos gastos da Previdência. Disponível em: < http://www.conjur.com.br/2006-

mar14/quem arcar_custo_empresa nao previdencia > Acesso em: 15/02/2017.

[3] Alves, Luiz Ferreira. Aplicação da norma NR-12 para circuitos de segurança utilizando controladores lógicos programáveis e atuadores pneumáticos. Disponível em: <http://www.tcc.sc.usp.br/tce/disponiveis/18/182500/tce-

16022016-180748/?\&lang=br> Acesso em: 19/02/2017

[4] Fórmica, Gualdo Amauri. Comentários à Nova Legislação do Trabalho. (Coleção Jurídico-Trabalhista) - $1^{\mathrm{o}}$ Vol. IOB Informações Objetivas, 2000.

[5] NM 273:2001. Segurança de máquinas - Dispositivos de intertravamento associados a proteções - Princípios para projeto e seleção. Disponível em: <https://www.google.com.br/url?sa=t\&rct=j\&q=\&esrc=s\&sourc $\mathrm{e}=$ web\&cd $=1 \& \mathrm{cad}=$ rja\&uact $=8 \& \mathrm{ved}=0$ ahUKEwiG8IHmkanSA hWFj5AKHb-

UAk0QFggcMAA\&url=http $\% 3 \mathrm{~A} \% 2 \mathrm{~F} \% 2 \mathrm{Fvipelevadores.com.br}$ \%2Farquivos\%2F1445452514.pdf\&usg=AFQjCNEjsWIkqMwK 0RR4u1kZyLaKLha02Q\&sig2=9Y64KnuxSAoQdFnP5WUHyw > Acesso em: 22/02/2017.

[6] Ribeiro Filho, Leonídio F. Técnicas de Segurança do Trabalho. $2^{\mathrm{a}}$. ed. São Paulo, Fundacentro, 2006.

[7] Siqueira, A. R.; Queiroz, M. F. F. Abordagem grupal em saúde do trabalhador. Mundo Saúde (São Paulo), v.24, p.4, 2001.
[8] Amâncio, Antônio Filho. Saúde, Trabalho e Formação Profissional. $4^{\mathrm{a}}$ edição. Rio de Janeiro: Fiocruz, 2007. ALMEIDA, I. M. Análise de Acidentes do Trabalho Como Ferramenta Auxiliar do Trabalho de Auditores Fiscais do Ministério do Trabalho e Emprego: Contribuições para a definição de orientações sobre a análise de acidentes conduzida por auditores fiscais.

[9] MINISTÉRIO DO TRABALHO. Norma Regulamentadora n. 18 (NR-18) - Condições e Meio Ambiente de Trabalho na Indústria da Construção. Brasília, 7 de julho de 1995.

[10] Nogueira F. Elementos do comportamento organizacional. $4^{\mathrm{a}}$ Edição. São Paulo: Pioneira, 2004.

[11] Zocchio, A. Prática de Prevenção de Acidentes: ABC da Segurança do Trabalho. Atlas, São Paulo, 2006.

[12] Schmitz, H. Eficiência coletiva: caminho de crescimento para a indústria de pequeno porte. Ensaios FEE, Porto AlegreRS, v.18,n², p.164-200,2007.

[13] Feitosa, José Celso. Modelo para aumentar a competitividade industrial: a transição para a gestão participativa. São Paulo: Edgard Blücher, 2001.

[14] De Souza G. F. Impactos da nova redação da NR 12 nas industrias: Disponível em

$<$ https://www.google.com.br/url?sa=t\&rct=j\&q=\&esrc=s\&sourc $\mathrm{e}=$ web\&cd=2\&cad=rja\&uact=8\&ved=0ahUKEwjf8JjdjanSAhV KOZAKHSjPByEQFggkMAE\&url=http\%3A\%2F\%2Frepositori o.roca.utfpr.edu.br\%2Fjspui\%2Fbitstream $\% 2 \mathrm{~F} 1 \% 2 \mathrm{~F} 3477 \% 2 \mathrm{~F} 1$ \%2FCT_CEEST_XXVII_2014_15.pdf\&usg=AFQjCNE08FQ5D cIu1hjUOmpfLrI9KziW2A\&sig2=ny0tddEynAFD0WEgePF64 w) Acesso em: 18/02/2017

[15] Feitosa, José Celso. Modelo para aumentar a competitividade industrial: a transição para a gestão participativa. São Paulo: Edgard Blücher, 2001.

[16] Portaria $n^{\circ}$ 197. PORTARIA SIT No 197 DE 17 DE DEZEMBRO DE 2010. Disponível em: <http://www.normaslegais.com.br/legislacao/portariasit197_201 $\underline{0 . h t m}>$ Acesso em: 21/02/2017. 